\title{
Glutaraldehyde and 2,3-butanediol treatment of bovine pericardium for aortic valve bioprosthesis in sheep: a preliminary study
}

\author{
Kai Ren ${ }^{1 \#}$, Weixun Duan ${ }^{1 \#}$, Zhuowen Liang" ${ }^{2 \#}$, Bo Yu ${ }^{1}$, Buying Li ${ }^{1}$, Zhengxiao Jin ${ }^{1}$, Yimin Zhao ${ }^{3}$ Chao Xue ${ }^{1}$, \\ Shiqiang Yu ${ }^{1}$, Jincheng Liu ${ }^{1}$, Xufeng Wei ${ }^{1}$ \\ ${ }^{1}$ Department of Cardiovascular Surgery, Xijing Hospital, Air Force Military Medical University, Xi'an, China; ${ }^{2}$ Medicine Institute of Orthopedics, \\ Xijing Hospital, Air Force Military Medical University, Xi'an, China; ${ }^{3}$ Jiahe Zhongbang Biotechnology Co., Ltd., Hangzhou, China \\ Contributions: (I) Conception and design: X Wei, J Liu; (II) Administrative support: S Yu; (III) Provision of study materials or patients: K Ren, W \\ Duan, Z Liang; (IV) Collection and assembly of data: B Yu, B Li, C Xue; (V) Data analysis and interpretation: Z Jin, Y Zhao; (VI) Manuscript \\ writing: All authors; (VII) Final approval of manuscript: All authors. \\ \#These authors contributed equally to this work. \\ Correspondence to: Shiqiang Yu; Jincheng Liu; Xufeng Wei. Department of Cardiovascular Surgery, Xijing Hospital, Air Force Military Medical \\ University, Xi'an, China. Email: yushiq@fmmu.edu.cn; liujch69@sina.com; weixf2004@126.com.
}

Background: Bovine pericardium can be used for cardiovascular repair surgeries, but challenges involving biocompatibility and durability remain. This study aimed to carry out pre-clinical testing of aortic valve replacement using an aortic valve prosthesis made of bovine pericardium modified with glutaraldehyde (GA) and 2,3-butanediol (BD).

Methods: The mechanical, plasma protein adsorption, platelet adhesion, collagenase digestion, and ninhydrin properties of the material (control vs. GA vs. GA + BD) were tested. All 3 tissues were implanted in rats and observed after 8 weeks under microscopy with alizarin red staining for calcification. Aortic valves made from the fully-treated material were implanted in sheep. A commercial bioprosthesis was used as control. Effectiveness and safety indicators were observed at 180 days after implantation.

Results: Compared with the control group, the GA + BD material showed higher elongation at breaking and tensile load (both $\mathrm{P}<0.05$ ), lower plasma protein adsorption, lower platelet adhesion, lower collagenase digestion, lower ninhydrin value, and higher cross-linking (all $\mathrm{P}<0.05$ ). After implantation in rat models, the GA + BD material showed little or no dissolution; there was no obvious calcification; and it was surrounded by a small amount of fibrosis, with peripheral capillary proliferation. After implantation in sheep models, the aortic valve leaflets of the experimental animals freely opened and closed, their surface was smooth, and no abnormal echo was observed. The echocardiographic results and hemodynamic were comparable between the two groups. All safety parameters were normal.

Conclusions: Modification of bovine pericardium with GA and BD results in a biomaterial with favorable properties for use as an aortic valve prosthesis.

Keywords: Aortic valve defect; aortic valve replacement; bioprosthesis; calcification; bovine pericardium; glutaraldehyde (GA); butanediol

Submitted Oct 23, 2020. Accepted for publication Dec 16, 2020.

doi: 10.21037/atm-20-7803

View this article at: http://dx.doi.org/10.21037/atm-20-7803 


\section{Introduction}

Among all patients treated for aortic valve disease, the prevalence of bicuspid aortic valves is $10.9 \%$, and survival after surgery is $76.7-91.7 \%$ (1). Aortic valve surgery is also indicated in cases of aortic stenosis and aortic regurgitation (2), which are conditions associated with rheumatic heart disease affecting 2 million Chinese adults (3).

Worldwide, the number of aortic replacements was about 290,000 in 2003 and is expected to be $\leq 850,000$ by 2050 (4). A number of prostheses are available for aortic valve replacement: surgical mechanical aortic valves, surgical biological aortic valves, and percutaneous aortic valves. The mechanical valves are associated with a long service time (25-30 years), but require life-long thromboprophylaxis and many patients are able to hear the sound of the leaflets closing. Biological aortic valves require less aggressive thromboprophylaxis and are not audible, but their service time is much shorter (10-15 years) (5). The main factors limiting the service life of biological aortic valve prostheses are infection, thrombosis, and calcification (5).

Because of the shortage of heart valve donors, xenografts (mainly bovine and porcine), remain attractive options $(5,6)$. The design of biological aortic valve prostheses with high biocompatibility and durability is a challenging (7) and complicated process $(5,8)$. Bovine pericardium tissue has been used for $>40$ years as a material for cardiovascular repair surgeries $(9,10)$; it is widely available, inexpensive, and reliable for such surgeries (6). Chemical modifications of bovine pericardium tissue lead to good durability $(11,12)$, but the risk of acute rejection of the xenograft remains. In fact, only the extracellular matrix (ECM) is required for valve integration and function $(13,14)$ and should be left as intact as possible, and all traces of antigens and DNA must be removed (7).

A new completely biological aortic valve prosthesis made from bovine pericardium has been developed by Jiahe Zhongbang Biotechnology Co., Ltd. (Hangzhou, Zhejiang, China). The bovine pericardium tissue was decellularized using glutaraldehyde (GA) and treated with 2,3-butanediol (BD) for anti-calcification. After testing its mechanical and biological properties both ex vivo and in vivo, the tissue was made into a functional aortic valve prosthesis that was tested in sheep, a species which can undergo cardiopulmonary bypass and have hemodynamics and coagulation similar to humans (15). Hence, the aim of the present study was to carry out pre-clinical testing of this new material for aortic valve replacement.
We present the following article in accordance with the ARRIVE reporting checklist (available at http://dx.doi. org/10.21037/atm-20-7803).

\section{Methods}

\section{Bovine pericardial materials and treatment with $G A$ cross- linking and butanediol}

Experiments were performed under a project license (No. 20160106) granted by the Animal Ethics Committee of the Air Force Military Medical University, in compliance with Chinese guidelines for the care and use of animals. The bovine pericardium was obtained within $2 \mathrm{~h}$ of warm ischemia. Excess fat and muscle were removed. After washing with saline, it was stored in phosphate-buffered saline (PBS) solution at $4{ }^{\circ} \mathrm{C}$. The average time of warm ischemia was $1 \pm 0.6 \mathrm{~h}$.

For decellularization, the bovine pericardium was rinsed twice in PBS for $10 \mathrm{~min} /$ time. After rinsing, the bovine pericardium was placed in Triton X-100 solution (Sigma, St. Louis, MO, USA) for $12 \mathrm{~h}$ and $0.1 \%$ trypsin for $3 \mathrm{~min}$. The bovine pericardium was rinsed twice with $\mathrm{PBS}$ for $10 \mathrm{~min} /$ time, and stored in glutaraldehyde (GA) at $4{ }^{\circ} \mathrm{C}$.

For cross-linking, the fat and muscle tissues were peeled off in $4{ }^{\circ} \mathrm{C}$ D-Hanks solution, rinsed twice with PBS, treated with $0.3 \%$ GA solution for $48 \mathrm{~h}$ at room temperature, and stored in $0.5 \%$ GA solution at $4{ }^{\circ} \mathrm{C}$ for later use. For modified anti-calcification treatment, the GA-treated bovine pericardium was rinsed twice with PBS, and treated with $100 \% \mathrm{BD}$ at $25^{\circ} \mathrm{C}$ for $120 \mathrm{~h}$. The bovine pericardium was stored in $0.5 \%$ GA at $4{ }^{\circ} \mathrm{C}$.

A total of 30 decellularized pericardial specimens were randomly divided into 3 groups ( $n=10 /$ group): (I) control group, the bovine pericardium material was decellularized without further treatment; (II) GA group, after decellularization, the pericardial material was treated with GA, as above; (III) GA + BD group, the decellularized material was first treated with GA, and then with BD.

\section{Mechanical properties}

The specimens of bovine pericardium were cut into $60 \mathrm{~mm} \times$ $6 \mathrm{~mm}$ pieces by the pulling strip cutting mold, and the middle test part was cut to $40 \mathrm{~mm} \times 4 \mathrm{~mm}$, which had a bell shape, 10 pieces/group. Before measurement, the test strips were placed in physiological saline. After soaking and rinsing, the test was carried out at an elongation rate of 
$20 \mathrm{~mm} / \mathrm{min}$. The elongation at breaking, tensile load, and tensile strength were measured on an electronic tensile test machine (Shanghai Instruments and Instruments Co., Ltd., Shanghai, China).

\section{Plasma protein adsorption}

The specimens were rinsed 3 times in PBS for $5 \mathrm{~min} /$ time. After rinsing, the specimens were placed in $10 \mathrm{~mL}$ of plasma and shaken at $37{ }^{\circ} \mathrm{C}$ for 3 days. After removal, they were rinsed 3 times for $5 \mathrm{~min} /$ time. After the samples were lyophilized and weighed, the homogenate was cut and placed in Tris buffer $(14 \mathrm{mmol} / \mathrm{L}$ Tris, $120 \mathrm{mmol} / \mathrm{L}$ sodium chloride, and $3 \mathrm{mmol} / \mathrm{L}$ potassium chloride, $\mathrm{pH} 7.4$ ) at $4{ }^{\circ} \mathrm{C}$ for $2 \mathrm{~min}$, centrifuged at $4^{\circ} \mathrm{C}$, and the protein concentration in the supernatant was determined by the Bradford's method. The protein adsorption rate was calculated as adsorbed protein $(\mu \mathrm{g}) /$ dry weight of the specimen $(\mathrm{mg})$.

\section{Platelet adhesion}

The specimens were placed in PBS and rinsed 3 times for $5 \mathrm{~min} /$ time. After rinsing, the specimens were placed in $10 \mathrm{~mL}$ of platelet-rich plasma at $37^{\circ} \mathrm{C}$ for $3 \mathrm{~h}$. The platelets were counted before and after the specimen were immersed. The platelet adhesion rate was calculated as (A - B)/dry weight of material $(\mathrm{mg})$, where $\mathrm{A}$ is the number of platelets in the plasma before immersion, and B is the number of platelets remaining after immersion).

\section{Collagenase digestion}

The specimens were rinsed with double-distilled water to remove chemicals, and then freeze-dried. After the sample was weighed $(10-15 \mathrm{mg})$, it was placed in an Eppendorf tube containing $1.2 \mathrm{~mL}$ of collagenase solution $(2 \mathrm{mg} / \mathrm{mL}$, $0.05 \mathrm{M}$ Tris buffer, and $0.36 \mathrm{mM} \mathrm{CaCl} 2, \mathrm{pH}$ 7.4). The solution was placed on a shaker at $37^{\circ} \mathrm{C}$ and $200 \mathrm{rpm}$ for $24 \mathrm{~h}$. The collagenase solution was removed, and the remaining samples were washed 3 times with water and then lyophilized. The percentage of degradation of each sample was calculated based on the remaining mass and initial mass of each sample, as residual weight/material weight $\times 100 \%$.

\section{Ninhydrin test}

The ninhydrin test was performed as previously described (16). A standard curve was plotted using a standard solution of calf serum albumin added with different gradient concentrations to $100 \mu \mathrm{L}$ of ninhydrin reagent at $100{ }^{\circ} \mathrm{C}$ for $10 \mathrm{~min}$. Absorbance was measured at $575 \mathrm{~nm}$ on a spectrophotometer (Shanghai Analyzer, Shanghai, China). About $10 \mathrm{mg}$ of each freeze-dried specimen were weighed and placed in a covered centrifuge tube. For collagen hydrolysis, $500 \mu \mathrm{L}$ of $6 \mathrm{M}$ hydrochloric acid $(\mathrm{HCl})$ were added to each centrifuge tube, and incubated at $100{ }^{\circ} \mathrm{C}$ for $24 \mathrm{~h}$. Then, the tube was capped and lyophilized. The residue was dissolved in water. The ninhydrin value was calculated as the amount of collagen protein/dry weight. The crosslinking degree was calculated as (ninth ketone value of untreated collagen - ninhydrin value of collagen after treatment)/ninhydrin value of untreated collagen $\times 100 \%$.

\section{Implantation}

The pericardial specimens of each group were selected to have equivalent thickness, cut into pieces of $1 \times 1 \times 0.1 \mathrm{~cm}^{3}$, and rinsed 3 times in physiological saline for $10 \mathrm{~min} /$ time. The Sprague Dawley (SD) rats [Air Force Military Medical University Laboratory Animals Center, Xi'an, China] were anesthetized with an intraperitoneal injection of $2 \%$ pentobarbital $(1 \mathrm{mg} / \mathrm{kg})$. After confirming anesthesia, a skin incision was made in the medial side of the back after disinfection. After hemostasis, all three specimens of different groups were implanted into the same rat. The distance between the different materials was $>2 \mathrm{~cm}$. After the material was fixed, the skin was sutured intermittently. After surgery, penicillin was injected at 40,000 U/kg. Vital signs and skin changes were observed.

\section{Calcification}

The rats were sacrificed 8 weeks after the pericardial specimens were implanted. The specimens were removed, excess fat and muscle tissues were removed, and they were fixed in $4 \%$ paraformaldehyde for $>2$ days. After hematoxylin and eosin (HE) staining and alizarin red staining, the specimens were observed under light microscopy (Olympus, Tokyo, Japan) to detect calcification.

\section{Sheep experiment of new whole biological aortic valve}

Adult healthy male sheep (Animal Laboratory Center of Air Force Military Medical University, Hangzhou, Zhejiang, China) ( $\mathrm{n}=13$ ), weighing about $60 \mathrm{~kg}$, were isolated for $\geq 48 \mathrm{~h}$ and fasted $12 \mathrm{~h}$ before surgery. The selection, feeding, 
monitoring, and experimental protocols of the experimental animals in this trial were conducted in accordance with the certification of the Animal Ethics Committee of the Air Force Military Medical University. The PERIMOUNT RSR Pericardial Bioprosthesis-Aortic 2800TFX (19 mm; Edwards Lifesciences Co., Ltd., Irvine, CA, USA) was used as control ( $n=3)$. The GA and BD treated material was used to manufacture a valve prosthesis similar in structure to that of the control prosthesis (Figure S1).

\section{Surgical procedure}

The biological valve was taken out of its aseptic package, placed in a stainless steel container, and washed 3 times with $0.9 \%$ saline. Artificial total aortic valve in situ replacement was performed with the sheep in the left lateral position, limbs fixed. The surgical field was disinfected with iodophor and sterile towels. The skin and subcutaneous tissue were cut through the fourth intercostal space of the right chest. The muscles were separated, the fourth rib was cut off, and the pleura was cut to enter the chest. The right lung was pulled to the dorsal side to fully expose the surgical field, fully freeing and revealing the aorta and the heart chamber. A purse line was sutured in the aorta and superior vena cava and inferior vena cava with 5.0 Prolene line, and extracorporeal circulation was performed after insertion of an aortic cannula and two venous cannulas. A cold needle was sutured at the root of the aorta. After the ascending aorta was blocked, cold perfusion was performed to stop the heart. The aortic root was dissected, aortic valve exposed, original aortic valve leaflets removed, and the bioaortic valve was fixed with a 12 -needle double-needle polyesterlined suture. The aortic incision was closed. The ascending aorta was opened, the heart was re-started, extracorporeal circulation was stopped, and the arteriovenous cannula was removed. Intraoperative echocardiography of the surface of the heart was performed to ensure no stenosis of the valve and leaflet activity. A chest drainage tube was placed to check for blood and oozing blood. The chest was closed layer by layer. Vasoactive drugs were routinely used after surgery, along with antibiotics to prevent infection. The tracheal intubation was removed after awaking.

\section{Postoperative care}

After the operation, the sheep was sent to the recovery room for observation and recording of vital signs (blood pressure and heart rate), urine volume, routine examination of blood gas, blood biochemical examination, drug analgesia, and to ensure that there was no effusion in the chest, pneumothorax, or atelectasis, etc. for $6 \mathrm{~h}$ after surgery. The chest drainage tube was removed the next morning. Routine intramuscular injection of antibiotics (such as cefazolin sodium and streptomycin sulfate) was performed for 3 days after surgery. At $6 \mathrm{~h}$ after removal of tracheal intubation, the test animals could eat. For 2 weeks after surgery, the animals were observed twice a day, and their daily behavior and mental status were recorded. The condition of the suture was observed and recorded. From 2 weeks after the operation, the animals were observed once a week. The animal weight was recorded every 2 weeks. Oral warfarin anticoagulation therapy $(2.5 \mathrm{mg} / \mathrm{d})$ was started $24 \mathrm{~h}$ after surgery. Indicators of effectiveness were examined at 180 days after surgery (hemodynamic performance and structural changes). Safety indicators (white blood cells, hemoglobin, platelet count, alanine aminotransferase (ALT), and blood urea nitrogen) were observed. The sacrifice of two test animals was conducted at 30 and 90 days after surgery. A total of six animals were sacrificed 180 days after surgery.

\section{Statistical analysis}

Data analysis was performed using SPSS 11.1 for Windows (SPSS Inc., IBM Corp., Chicago, IL, USA). All data were expressed as means \pm standard deviation $(\mathrm{SD})$ and analyzed using analysis of variance (ANOVA) with the least significant difference (LSD) post hoc test, or the student $t$-test, as appropriate. Any $\mathrm{P}$ values $<0.05$ were considered statistically significant.

\section{Results}

\section{Mechanical test}

The elongation at breaking of the GA group was significantly higher than that in the control group $(\mathrm{P}<0.05)$, and the elongation at breaking in the GA $+\mathrm{BD}$ group was significantly higher than that in the GA group $(\mathrm{P}<0.05)$. The tensile load of the GA + BD group was significantly higher than that of the control and GA groups (both $\mathrm{P}<0.05$ ); there was no significant difference between the GA and control groups. There were no differences between the 3 groups regarding the tensile strength (Table 1). 
Table 1 Mechanical testing

\begin{tabular}{lccc}
\hline Group & Elongation at breaking (\%) & Tensile load $(\mathrm{N})$ & Tensile strength $(\mathrm{MPa})$ \\
\hline Control & $16.3 \pm 3.5$ & $22.0 \pm 2.8$ & $18.8 \pm 3.3$ \\
GA & $30.5 \pm 2.6^{*}$ & $23.2 \pm 4.3$ & $18.2 \pm 2.6$ \\
GA + BD & $47.1 \pm 8.2^{\star *}$ & $41.5 \pm 1.7^{\star *}$ & $19.0 \pm 2.1$ \\
\hline
\end{tabular}

*, compared with the control group, $\mathrm{P}<0.05$; ", compared with the GA group, $\mathrm{P}<0.05$. GA, glutaraldehyde; BD, 2,3-butanediol.

Table 2 Plasma protein adsorption test

\begin{tabular}{lc}
\hline Group & Absorption $(\mathrm{g} / \mathrm{kg})$ \\
\hline Control & $0.14 \pm 0.02$ \\
GA & $0.20 \pm 0.03^{*}$ \\
GA + BD & $0.13 \pm 0.02^{\star \#}$
\end{tabular}

*, compared with the control group, $\mathrm{P}<0.05$; ", compared with the GA group, $\mathrm{P}<0.05$. GA, glutaraldehyde; BD, 2,3-butanediol.

Table 3 Platelet adhesion test

\begin{tabular}{lc}
\hline Group & Platelet adhesion $\left(10^{12} / \mathrm{kg}\right)$ \\
\hline Control & $1.34 \pm 0.21$ \\
GA & $1.93 \pm 0.08^{*}$ \\
GA + BD & $1.13 \pm 0.12^{* \#}$ \\
\hline
\end{tabular}

*, compared with the control group, $\mathrm{P}<0.05$; ", compared with the GA group, $\mathrm{P}<0.05$. GA, glutaraldehyde; $\mathrm{BD}$, 2,3-butanediol.

Table 4 Collagenase digestion test

\begin{tabular}{lc}
\hline Group & Undigested rate (\%) \\
\hline Control & $9.8 \pm 4.5$ \\
GA & $77.1 \pm 16.7^{\star}$ \\
GA + BD & $82.6 \pm 8.9^{* \#}$ \\
\hline
\end{tabular}

*, compared with the control group, $\mathrm{P}<0.05$; " , compared with the GA group, $\mathrm{P}<0.05$. GA, glutaraldehyde; BD, 2,3-butanediol.

Table 5 Ninhydrin test

\begin{tabular}{lcc}
\hline Group & Ninhydrin (\%) & Cross-section (\%) \\
\hline Control & $26.1 \pm 8.6$ & - \\
GA & $14.9 \pm 3.5^{\star}$ & $56.7 \pm 3.9$ \\
GA + BD & $11.5 \pm 4.6^{\star \#}$ & $78.1 \pm 2.8^{\#}$ \\
\hline
\end{tabular}

*, compared with the control group, $\mathrm{P}<0.05$; ", compared with the GA group, $\mathrm{P}<0.05$. GA, glutaraldehyde; BD, 2,3-butanediol.

\section{Plasma protein adsorption}

The protein adsorption rate of bovine pericardium material treated with GA + BD was significantly lower than that of the GA group $(\mathrm{P}<0.05)$, and significantly lower than that of the control group $(\mathrm{P}<0.05)$ (Table 2).

\section{Platelet adbesion}

The platelet adhesion rate of the GA group was significantly higher than that of the control group $(\mathrm{P}<0.05)$. The platelet adhesion rate of the GA + BD group was significantly lower than that of the GA and control groups (both $\mathrm{P}<0.05$ ) (Table 3).

\section{Collagenase digestion}

The undigested rate of the bovine pericardium material was significantly increased compared with the control group after GA treatment $(\mathrm{P}<0.05)$, and the undigested rate of GA $+\mathrm{BD}$ treatment group was significantly further increased $(\mathrm{P}<0.05)$ (Table 4).

\section{Ninhydrin test}

After treatment with GA, the ninhydrin value of the bovine pericardial material significantly decreased compared with the control group $(\mathrm{P}<0.05)$, and the combination $\mathrm{GA}+\mathrm{BD}$ further decreased the ninhydrin value $(\mathrm{P}<0.05)$. The degree of crosslinking after treatment in the GA group was $<\mathrm{GA}+$ $\mathrm{BD}$ group $(\mathrm{P}<0.05)($ Table 5$)$.

\section{Implantation in rats}

In the control group, the bovine pericardium material showed flaky calcification; the tissue was partially dissolved, surrounded by fibrous tissue, and the material had little capillary proliferation. In the GA group, the material 

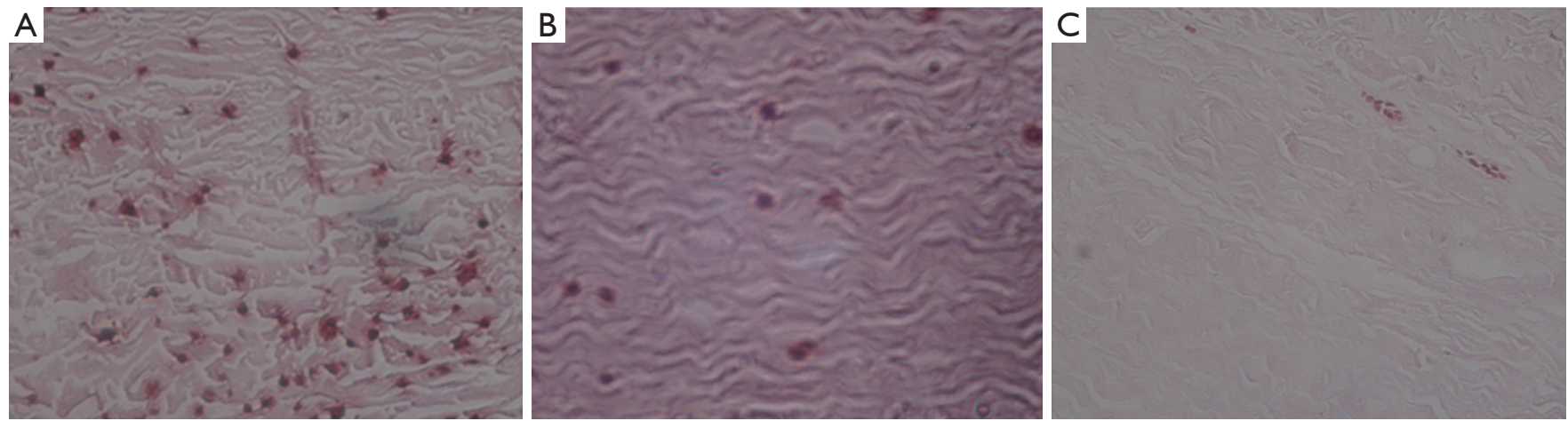

Figure 1 Histological observation of the new biomaterials after implantation for 8 weeks in rats (alizarin red staining, $\times 100$ ). (A) Decellularized; (B) Decellularized and glutaraldehyde; (C) Decellularized, glutaraldehyde, and 2,3-butanediol.
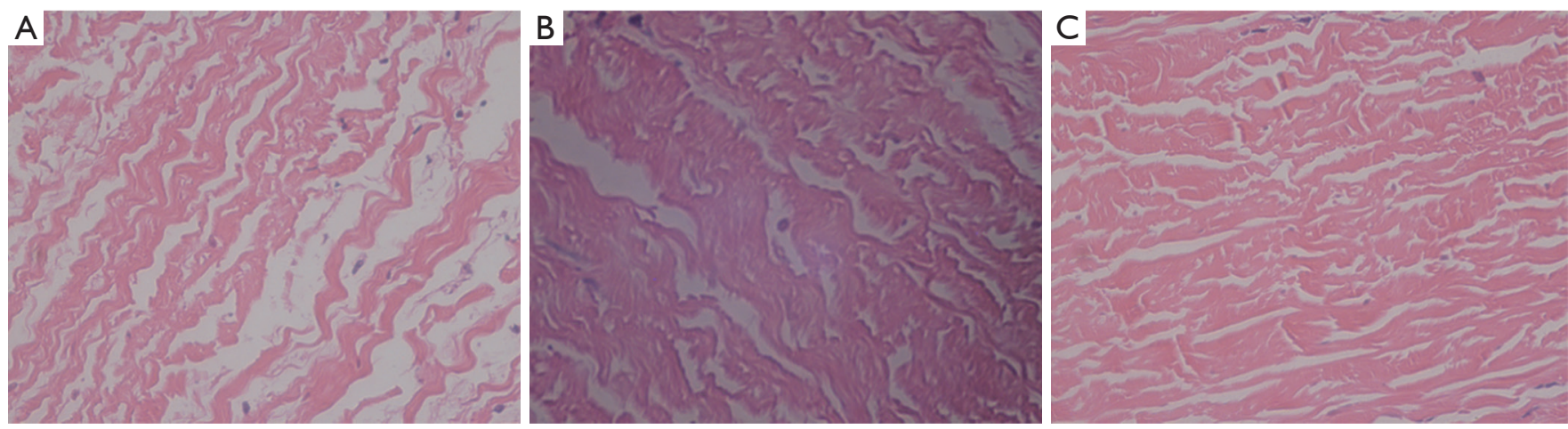

Figure 2 Histological observation of the new biomaterials after implantation for 8 weeks in rats (hematoxylin and eosin, $\times 100$ ). (A) Decellularized; (B) Decellularized and glutaraldehyde; (C) Decellularized, glutaraldehyde, and 2,3-butanediol.

showed little or no dissolution; there was a small amount of scattered calcification; it was surrounded by a small amount of fibrosis, with visible capillary proliferation. In the GA + BD group, the material showed little or no dissolution; there was no obvious calcification; it was surrounded by a small amount of fibrosis, with peripheral capillary proliferation (Alizarin red staining, Figure 1).

The histological examination (HE staining) showed, in the control group, that the biomaterial collagen fibers were haphazardly arranged, with obvious glassy degeneration, collagen fiber breakage and calcification, small amounts of fibrous tissue, and a small amount of lymphocyte infiltration (Figure 2A). In the GA group, the biomaterial collagen fibers were neatly arranged compared with the control group, with a small amount of glassy degeneration, and a small amount of scattered calcification; there was less fibrous tissue hyperplasia, and a small amount of lymphocyte infiltration (Figure $2 B$ ). In the GA + BD group, biomaterial collagen fibers were arranged neatly; a small amount of glassy degeneration and degeneration could be seen; fibrous tissue proliferation was less, with a small amount of lymphocyte infiltration (Figure 2C).

\section{Aortic valve implantation in sheep}

All the experimental animals successfully underwent implantation of the artificial heart valve under general anesthesia and cardiopulmonary bypass. The anesthesia time was $255 \pm 53 \mathrm{~min}$. The average extracorporeal circulation time was $119 \pm 31 \mathrm{~min}$. The sheep were able to stand within $2 \mathrm{~h}$ of surgery, and began to consume water within $4 \mathrm{~h}$. The drainage tube was removed within $24 \mathrm{~h}$ following the operation, and the average drainage volume was $81 \pm 27 \mathrm{~mL}$ (Figure 3).

An experimental animal in the 180-day group died unexpectedly on day 167 due to hemorrhage. Another 

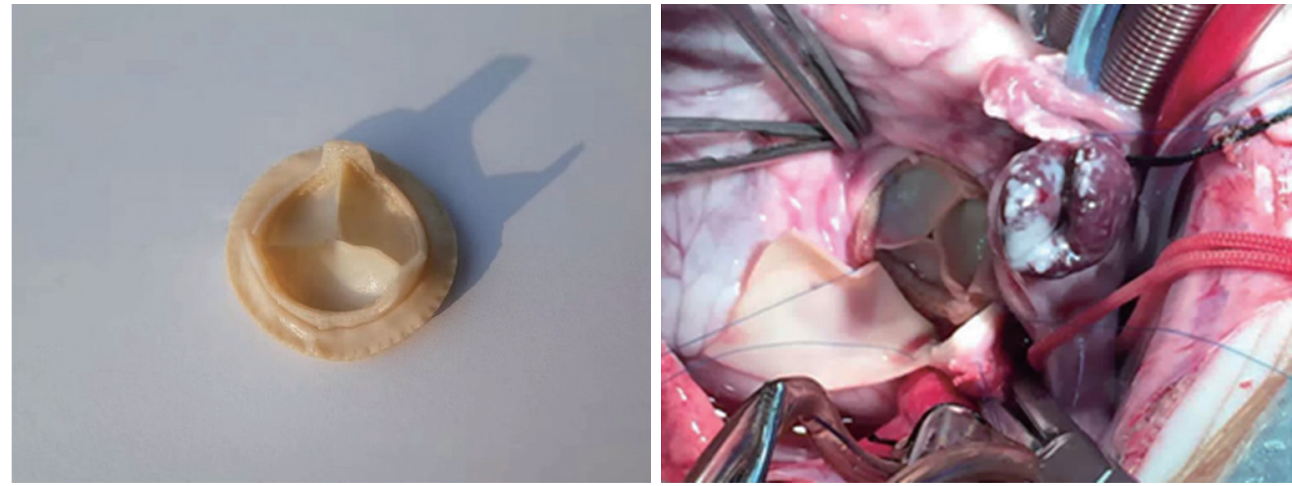

Figure 3 Whole aortic valve bioprosthesis before and after implantation in sheep.
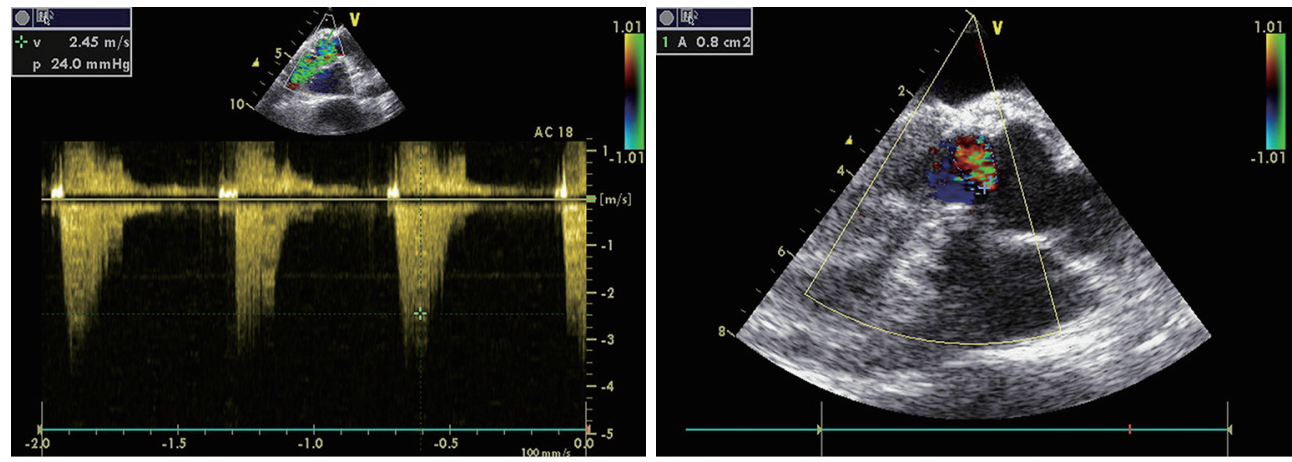

Figure 4 Echocardiographic results after total aortic valve bioprosthesis implantation in sheep.

experimental animal implanted with the control valve accidentally died on day 172 due to thrombosis.

The average body weight at the end of the experiment was significantly higher than that of the preoperative experimental animals $(66 \pm 8.5 v s .60 \pm 10.8 \mathrm{~kg}, \mathrm{P}<0.05)$.

Surface echocardiography was performed. The aortic valve leaflets of the experimental animals freely opened and closed, their surface was smooth, and no abnormal echo was observed. The position, echo signal, and movement of the valve leaflets were not abnormal. Flow and Doppler showed that the blood flow velocity through the artificial heart valve flap was normal, but a little lower in the experimental group. No significant reflux was observed in each valve (Figure 4). The echocardiographic results and hemodynamics were comparable between the 2 groups, except that the experimental group showed slightly lower left ventricular systolic pressure $(42.0 \pm 14.6$ vs. $45.2 \pm 13.1 \mathrm{mmHg}$, $\mathrm{P}<0.05)$ and lower pulmonary artery pressure $(8.3 \pm 0.6$ vs. $11.5 \pm 4.4 \mathrm{mmHg}$ ) (Tables 6,7).

No renal or liver function impairment were detected following implantation. The results of post-operative blood draws for laboratory testing were as follows. The mean white blood cell count was $(11.5 \pm 2.4) \times 10^{9} / \mathrm{L}$ and $(10.9 \pm 2.3) \times 10^{9} / \mathrm{L}$ before surgery and at 180 days, respectively (Figure $5 A$ ). The mean hemoglobin levels were $109.7 \pm 15.9 \mathrm{~g} / \mathrm{L}$ before surgery and $112.3 \pm 14.6 \mathrm{~g} / \mathrm{L}$ at the end of the experiment (Figure $5 B$ ). The mean platelet count was $(318.3 \pm 71.4) \times 10^{9} / \mathrm{L}$ before operation; it increased significantly on the $7^{\text {th }}$ day after surgery, and then gradually decreased. The average platelet count at 180 days was $(261.8 \pm 77.3) \times 10^{9} / \mathrm{L}$ (Figure 5 C). The mean levels of ALT were $20.2 \pm 9.5 \mathrm{IU} / \mathrm{L}$ before surgery, significantly increased on the first day after surgery, and gradually decreased by 7 days after surgery; the mean ALT at the end of the experiment were $15.3 \pm 4.0 \mathrm{IU} / \mathrm{L}$ (Figure $5 \mathrm{D}$ ). The preoperative mean value of urea nitrogen was $9.4 \pm 4.2 \mathrm{mmol} / \mathrm{L}$, and the mean value of urea nitrogen at the end of the experiment was $8.6 \pm 1.6 \mathrm{mmol} / \mathrm{L}$ (Figure 5 E).

Histopathological examination showed that the annulus and leaflets of the artificial aortic valve were roughly normal 
Table 6 Echocardiographic results of artificial whole biological heart valves

\begin{tabular}{lcc}
\hline Echocardiographic indicator & Control $(\mathrm{n}=3)$ & Experimental group $(\mathrm{n}=10)$ \\
\hline EOA $\left(\mathrm{cm}^{2}\right)$ & $1.08 \pm 0.44$ & $1.12 \pm 0.53$ \\
Return percentage $(\%)$ & $1.42 \pm 0.47$ & $1.47 \pm 0.49$ \\
Blood flow $(\mathrm{m} / \mathrm{s})$ & $1.58 \pm 0.38$ & $1.32 \pm 0.56^{*}$ \\
LVSP $(\mathrm{mmHg})$ & $75.42 \pm 8.58$ & $75.96 \pm 8.27$ \\
LVEDP $(\mathrm{mmHg})$ & $4.82 \pm 2.35$ & $4.83 \pm 3.58$ \\
Ejection fraction $(\%)$ & $59 \pm 5$ & $57 \pm 8$ \\
\hline
\end{tabular}

*, $\mathrm{P}<0.05$ vs. control. EOA, effective orifice area; LVSP, left ventricular systolic pressure; LVEDP, left ventricular end diastolic pressure.

Table 7 Hemodynamic changes after aortic valve replacement

\begin{tabular}{lcc}
\hline Hemodynamic indicator & Control $(\mathrm{n}=3)$ & Experimental group $(\mathrm{n}=10)$ \\
\hline Mean arterial pressure $(\mathrm{mmHg})$ & $90.0 \pm 12.9$ & $88.4 \pm 15.5$ \\
Left ventricular systolic pressure $(\mathrm{mmHg})$ & $45.2 \pm 13.1$ & $42.0 \pm 14.6^{\star}$ \\
Pulmonary artery pressure $(\mathrm{mmHg})$ & $11.5 \pm 4.4$ & $8.3 \pm 0.6^{\star}$ \\
Central venous pressure $(\mathrm{mmHg})$ & $3.0 \pm 4.1$ & $2.5 \pm 3.2$ \\
\hline
\end{tabular}

*, $\mathrm{P}<0.05$ vs. controls.

collagen tissue. The collagen fibers of the annulus were hyaline degenerated, and a portion of the leaflet collagen fibers were partially calcified. There was no obvious degeneration or necrosis in the leaflet tissue. Foreign bodies and a small amount of multinucleated giant cells were observed at the edge of the wall tissue. The aortic wall was smooth and the collagen fibrous tissue proliferated, with local hyaline degeneration. The cardiac tissue specimen showed no obvious fibrosis. A few areas of infarction could be seen in local muscle fiber rupture. A small amount of lymphocytic infiltration and small tumor muscle fiber dissolution could be seen scattered in small focal calcification. Lung tissue showed visible normal alveolar structure. Most of the experimental animal lung tissue showed alveolar wall telangiectasia congestion, some alveoli with cavity expansion, and a small amount of lymphocyte infiltration. The liver, kidney, spleen, and brain showed normal structural morphology, without obvious bleeding or necrosis (Figure 6).

Calcium content analysis showed that the content of annulus calcium in the experimental group was $3.66 \mu \mathrm{g} / \mathrm{mg}$. The calcium content of the annulus of the control group was $8.23 \mu \mathrm{g} / \mathrm{mg}$ (Table 8).

\section{Discussion}

Bovine pericardium can be used for cardiovascular repair surgeries $(9,10)$, but biocompatibility and durability remain as challenges $(5,7,8)$. The present study aimed to carry out pre-clinical testing of aortic valve replacement using an aortic valve prosthesis composed of bovine pericardium modified using GA and BD. Taken together, the findings suggest that the degree of collagen cross-linking of bovine pericardium biomaterials was increased with GA, and further so with GA and BD. Plasma protein adsorption and platelet adhesion experiments confirmed that GA and $\mathrm{BD}$ treatment could improve the blood compatibility of the bovine pericardial biomaterials. Furthermore, treatment with GA and BD could further improve the physicochemical properties of bovine pericardium materials, which is beneficial to improve blood compatibility and slow down the calcification process. Hence, the GA and BD treated biomaterial showed good bio-compatibility, and may be suitable for in vivo use. This was confirmed after implantation in sheep. The aortic valve leaflets of the experimental animals freely opened and closed, their surface was smooth, and no abnormal echo was observed. The echocardiographic results and hemodynamics were 

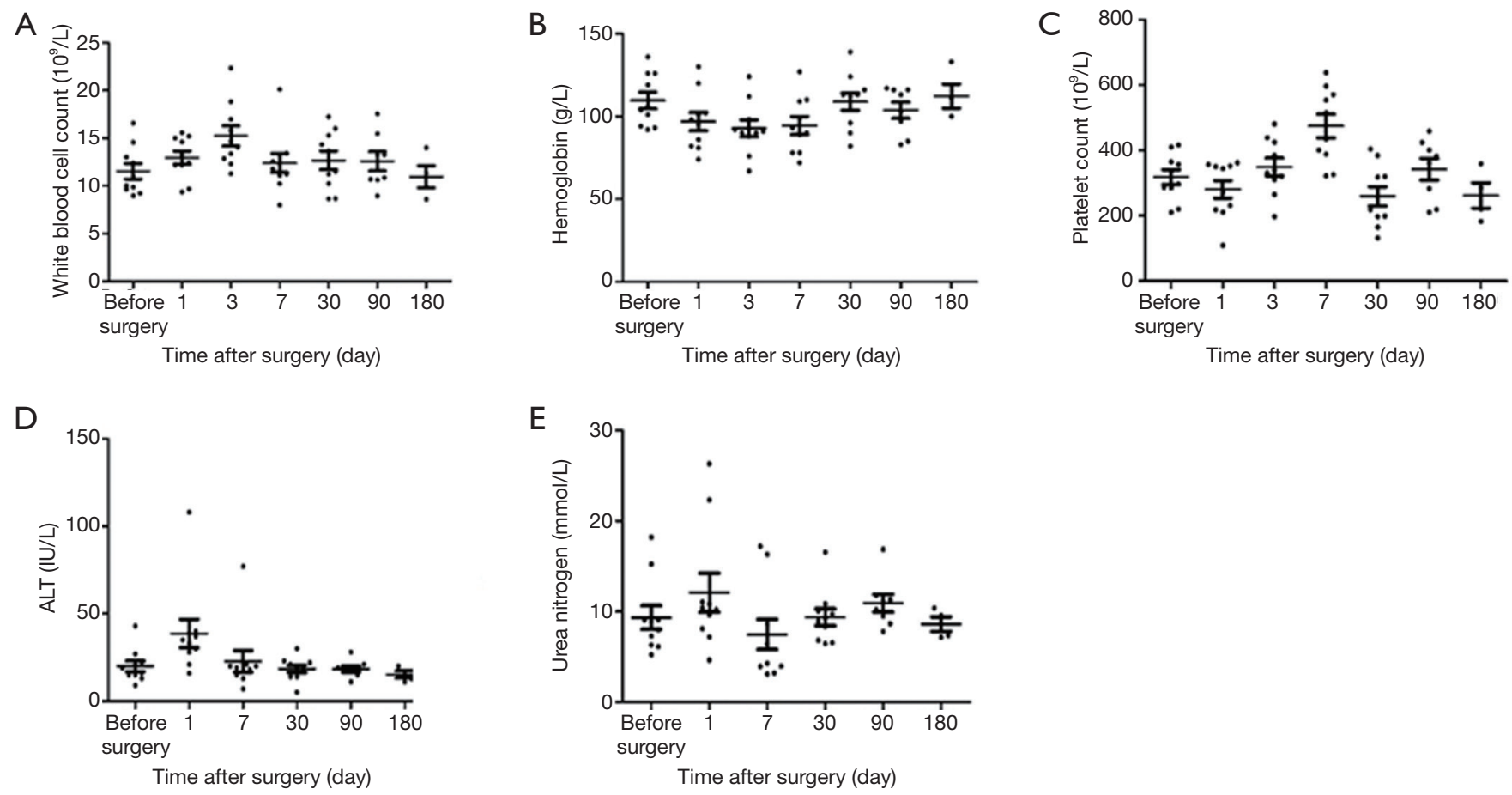

Figure 5 Laboratory test. (A) White blood cell count; (B) hemoglobin; (C) platelet count; (D) alanine transaminase (ALT); (E) urea nitrogen.

generally comparable between the two groups. All safety parameters were normal. Hence, based on these findings, modification of bovine pericardium with GA and BD results in a biomaterial with favorable properties for its use as aortic valve prosthesis.

The optimal aortic valve prosthesis would have a long life and require no thromboprophylaxis. Whether bioprostheses made of bovine pericardium result in better survival outcomes than porcine ones is currently controversial (17-19). For now, available clinical results suggest that both can be used for the treatment of patients needing aortic valve replacement (20). Nevertheless, bioprostheses made of bovine pericardium have been reported as having more advantageous hemodynamics and better prosthesis-patient mismatch than their porcine counterparts $(17,21,22)$.

Structural valve degeneration is one of the main causes of valve dysfunction and prosthesis failure secondary to stenosis, regurgitation, or the combination of both $(23,24)$. Different clinical definitions of structural valve degeneration have been proposed (23). Bovine bioprostheses are more prone to failure due to degeneration, while porcine bioprostheses are more prone to failure due to leaflet tear (7). Bovine structural valve degeneration results from leaflet calcification and degradation (23). The GA treatment used to make the bioprosthesis immunologically inert leads to free aldehyde groups that are prone to a passive calcification process (25). In the present study, the GA $+\mathrm{BD}$ material had better mechanical properties, lower collagenase digestibility, lower ninhydrin value, and lower calcification (as a subcutaneous implant) than the control and GA materials. In the sheep implantation experiment, calcification was lower in the GA + BD prostheses than in the commercial ones.

Early valve thrombosis occurs in up to $15 \%$ of patients receiving an aortic valve bioprosthesis (26-29). Valve thrombosis, in addition to the risk of mechanical failure due to the thrombus, might induce a remodeling of the leaflets that could accelerate their failure (23). In the present study, the GA + BD material showed lower plasma protein adsorption and platelet adhesion capacity than the control material.

The present study suggests that the hemodynamics of the GA + BD prosthesis could be similar, at least over 6 months, to a commercially available prosthesis. The sheep with the GA + BD prosthesis did not develop significant thrombosis or valve failure. Blood flow, left ventricular systolic pressure, 

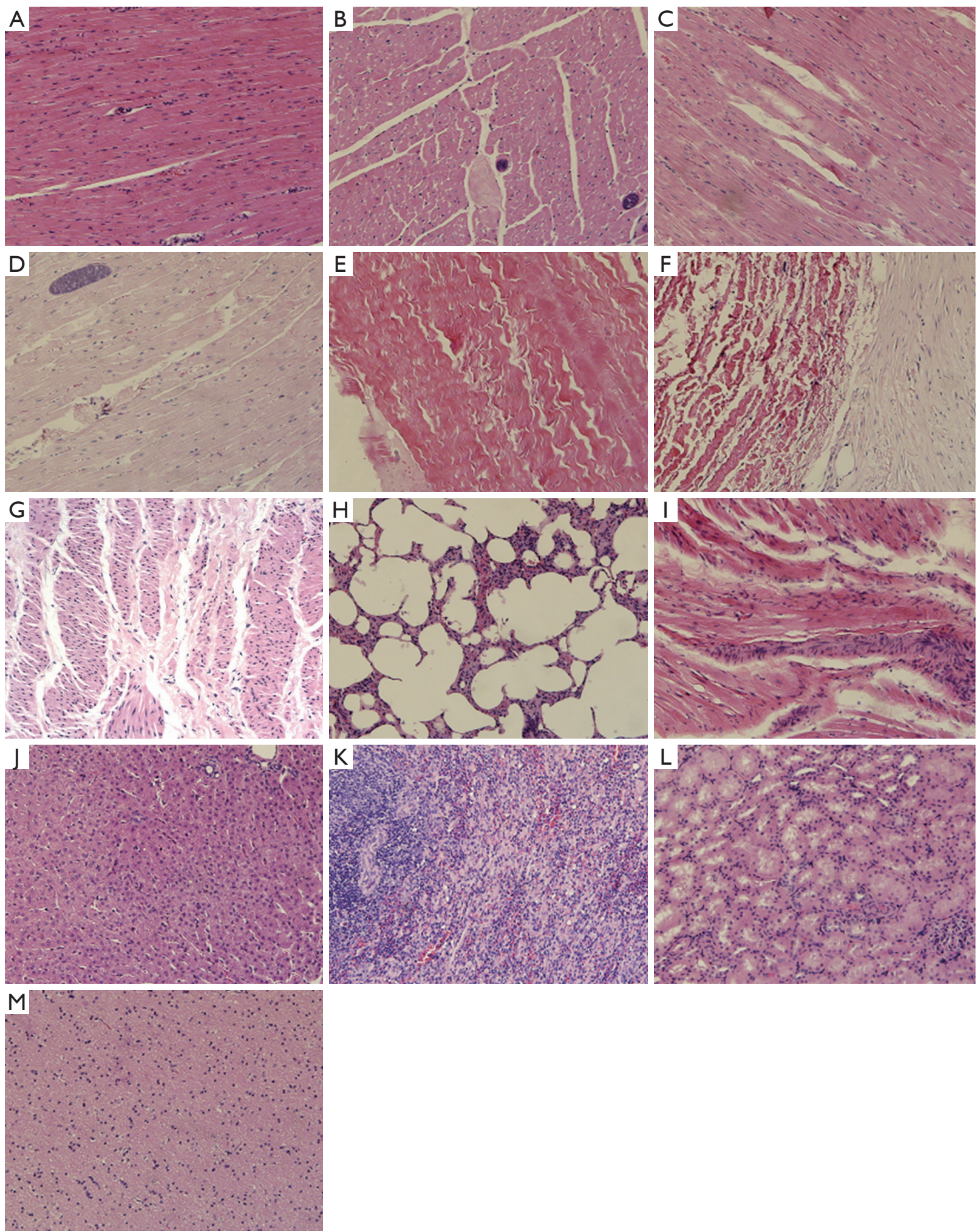

Figure 6 Histological observation of different organs after implantation of the aortic valve bioprosthesis in sheep for 180 days. (A) Left ventricle; (B) right ventricle; (C) left atrium; (D) right atrium; (E) prosthetic valve leaflets; (F) artificial annulus; (G) perivascular tissue; (H) aortic wall; (I) lung; (J) liver; (K) spleen; (L) kidney; (M) brain. Hematoxylin and eosin, $\times 200$. 
Table 8 Calcium content in the aortic valve prostheses

\begin{tabular}{lcc}
\hline Sheep ${ }^{\#}$ & Experimental group $(\mu \mathrm{g} / \mathrm{mg})$ & Control $(\mu \mathrm{g} / \mathrm{mg})$ \\
\hline 01 & 1.64 & 2.2 \\
02 & 0.92 & 15.09 \\
03 & 1.08 & 7.4 \\
04 & 2.99 & - \\
05 & 16.81 & - \\
06 & 4.52 & - \\
07 & 1.51 & - \\
08 & 1.44 & - \\
09 & 2.03 & - \\
\hline
\end{tabular}

\#, one experimental animal in the 180-day group died unexpectedly on day 167. One experimental animal implanted in the control valve accidentally died on day 172 .

and pulmonary pressure were a little lower than in the control group, but this could be due to the small sample size or to the bioprosthesis design. Indeed, the present study only examined the GA and GA + BD material, not the optimal prosthesis design. Additional studies are needed to examine this issue. Longer follow-up of implanted animals would also be required, as well as the extent of the need for thromboprophylaxis.

In conclusion, both the ex vivo and in vivo experiments suggest that the use of the GA $+\mathrm{BD}$ treated bovine pericardium as a material for making aortic valve bioprosthesis could result in good effectiveness and could eventually be amenable to clinical testing after the prerequisite rigorous testing. This material could improve outcomes for patients requiring aortic valve replacement, and could eventually be used to manufacture a variety of valves.

\section{Acknowledgments}

Funding: The study was supported by the National Natural Science Foundation of China (81572151; 31370996).

\section{Footnote}

Reporting Checklist: The authors have completed the ARRIVE reporting checklist. Available at http://dx.doi. org/10.21037/atm-20-7803

Data Sharing Statement: Available at http://dx.doi. org/10.21037/atm-20-7803

Conflicts of Interest: All authors have completed the ICMJE uniform disclosure form (available at http://dx.doi. org/10.21037/atm-20-7803). The authors have no conflicts of interest to declare.

Ethical Statement: The authors are accountable for all aspects of the work in ensuring that questions related to the accuracy or integrity of any part of the work are appropriately investigated and resolved. Experiments were performed under a project license (No. 20160106) granted by the Animal Ethics Committee of the Air Force Military Medical University, in compliance with Chinese guidelines for the care and use of animals.

Open Access Statement: This is an Open Access article distributed in accordance with the Creative Commons Attribution-NonCommercial-NoDerivs 4.0 International License (CC BY-NC-ND 4.0), which permits the noncommercial replication and distribution of the article with the strict proviso that no changes or edits are made and the original work is properly cited (including links to both the formal publication through the relevant DOI and the license). See: https://creativecommons.org/licenses/by-nc-nd/4.0/.

\section{References}

1. Wang X, Wang W. Prevalence of Bicuspid Aortic Valve in Chinese Patients with Aortic Valve Disease: A Systematic 
Review. J Heart Valve Dis 2017;26:274-80.

2. Afifi A, Hosny H, Yacoub M. Rheumatic aortic valve disease-when and who to repair? Ann Cardiothorac Surg 2019;8:383-9.

3. Zhimin W, Yubao Z, Lei S, et al. Prevalence of chronic rheumatic heart disease in Chinese adults. Int J Cardiol 2006;107:356-9.

4. Yacoub MH, Takkenberg JJ. Will heart valve tissue engineering change the world? Nat Clin Pract Cardiovasc Med 2005;2:60-1.

5. Musumeci L, Jacques N, Hego A, et al. Prosthetic Aortic Valves: Challenges and Solutions. Front Cardiovasc Med 2018;5:46.

6. Iop L, Palmosi T, Dal Sasso E, et al. Bioengineered tissue solutions for repair, correction and reconstruction in cardiovascular surgery. J Thorac Dis 2018;10:S2390-411.

7. Arsalan M, Walther T. Durability of prostheses for transcatheter aortic valve implantation. Nat Rev Cardiol 2016;13:360-7.

8. Fraser AG, Daubert JC, Van de Werf F, et al. Clinical evaluation of cardiovascular devices: principles, problems, and proposals for European regulatory reform. Report of a policy conference of the European Society of Cardiology. Eur Heart J 2011;32:1673-86.

9. Pires AC, Saporito WF, Cardoso SH, et al. Bovine pericardium used as a cardiovascular patch. Heart Surg Forum 1999;2:60-9.

10. Neethling WM, Strange G, Firth L, et al. Evaluation of a tissue-engineered bovine pericardial patch in paediatric patients with congenital cardiac anomalies: initial experience with the ADAPT-treated CardioCel(R) patch. Interact Cardiovasc Thorac Surg 2013;17:698-702.

11. Breymann T, Thies WR, Boethig D, et al. Bovine valved venous xenografts for RVOT reconstruction: results after 71 implantations. Eur J Cardiothorac Surg 2002;21:70310; discussion 710 .

12. Yuan SM. The Contegra valved bovine conduit: a biomaterial for the surgical treatment of congenital heart defects. Arq Bras Cardiol 2012;99:1159-66.

13. Dohmen PM, da Costa F, Yoshi S, et al. Histological evaluation of tissue-engineered heart valves implanted in the juvenile sheep model: is there a need for in-vitro seeding? J Heart Valve Dis 2006;15:823-9.

14. Gallo M, Naso F, Poser H, et al. Physiological performance of a detergent decellularized heart valve implanted for 15 months in Vietnamese pigs: surgical procedure, follow-up, and explant inspection. Artif Organs 2012;36:E138-50.

15. Katz MG, Kendle AP, Fargnoli AS, et al. Sheep (Ovis aries) as a model for cardiovascular surgery and management before, during, and after cardiopulmonary bypass. J Am Assoc Lab Anim Sci 2015;54:7-8.

16. Coffey JW, Fiedler-Nagy C, Georgiadis AG, et al. Digestion of native collagen, denatured collagen, and collagen fragments by extracts of rat liver lysosomes. J Biol Chem 1976;251:5280-2.

17. Chan V, Kulik A, Tran A, et al. Long-term clinical and hemodynamic performance of the Hancock II versus the Perimount aortic bioprostheses. Circulation 2010;122:S10-6.

18. Said SM, Ashikhmina E, Greason KL, et al. Do pericardial bioprostheses improve outcome of elderly patients undergoing aortic valve replacement? Ann Thorac Surg 2012;93:1868-74; discussion 1874-5.

19. Dalmau MJ, González-Santos JM, Blázquez JA, et al. Hemodynamic performance of the Medtronic Mosaic and Perimount Magna aortic bioprostheses: five-year results of a prospectively randomized study. Eur J Cardiothorac Surg 2011;39:844-52; discussion 852.

20. Glaser N, Jackson V, Franco-Cereceda A, et al. Survival after Aortic Valve Replacement with Bovine or Porcine Valve Prostheses: A Systematic Review and Meta-Analysis. Thorac Cardiovasc Surg 2019;67:282-90.

21. Sharma V, Deo SV, Altarabsheh SE, et al. Comparison of the early haemodynamics of stented pericardial and porcine aortic valves. Eur J Cardiothorac Surg 2015;47:4-10.

22. Ruzicka DJ, Hettich I, Hutter A, et al. The complete supraannular concept: in vivo hemodynamics of bovine and porcine aortic bioprostheses. Circulation 2009;120:S139-45.

23. Rodriguez-Gabella T, Voisine P, Puri R, et al. Aortic Bioprosthetic Valve Durability: Incidence, Mechanisms, Predictors, and Management of Surgical and Transcatheter Valve Degeneration. J Am Coll Cardiol 2017;70:1013-28.

24. Côté N, Pibarot P, Clavel MA. Incidence, risk factors, clinical impact, and management of bioprosthesis structural valve degeneration. Curr Opin Cardiol 2017;32:123-9.

25. Chen W, Schoen FJ, Levy RJ. Mechanism of efficacy of 2-amino oleic acid for inhibition of calcification of glutaraldehyde-pretreated porcine bioprosthetic heart valves. Circulation 1994;90:323-9.

26. Puri R, Auffret V, Rodés-Cabau J. Bioprosthetic Valve Thrombosis. J Am Coll Cardiol 2017;69:2193-211.

27. Chakravarty T, Søndergaard L, Friedman J, et al. Subclinical leaflet thrombosis in surgical and transcatheter bioprosthetic aortic valves: an observational study. Lancet 2017;389:2383-92. 
28. Makkar RR, Fontana G, Jilaihawi H, et al. Possible Subclinical Leaflet Thrombosis in Bioprosthetic Aortic Valves. N Engl J Med 2015;373:2015-24.

29. Mangione FM, Jatene T, Gonçalves A, et al. Leaflet

Cite this article as: Ren $\mathrm{K}$, Duan $\mathrm{W}$, Liang $\mathrm{Z}$, Yu B, Li B, Jin Z, Zhao Y, Xue C, Yu S, Liu J, Wei X. Glutaraldehyde and 2,3-butanediol treatment of bovine pericardium for aortic valve bioprosthesis in sheep: a preliminary study. Ann Transl Med 2020;8(24):1668. doi: 10.21037/atm-20-7803
Thrombosis in Surgically Explanted or Post-Mortem TAVR Valves. JACC Cardiovasc Imaging 2017;10:82-5.

(English Language Editor: J. Jones) 


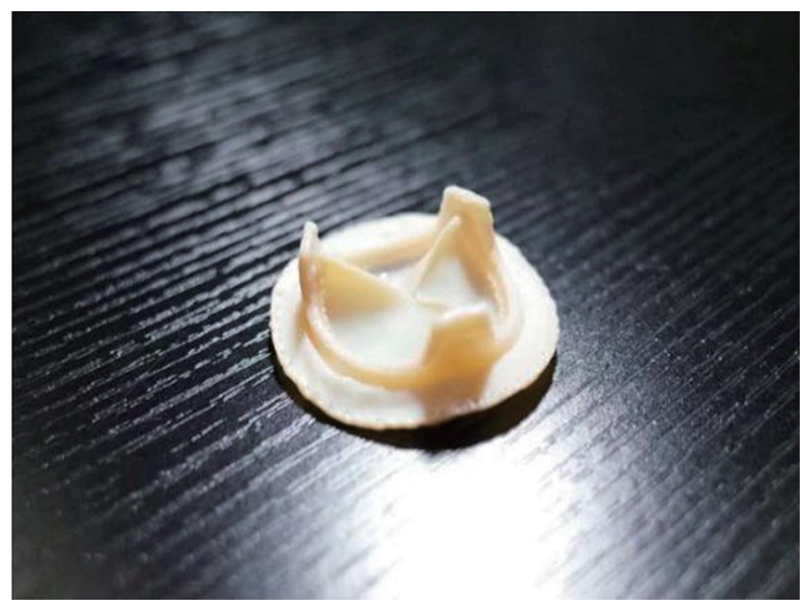

Figure S1 Aortic valve made from the glutaraldehyde and 2,3-butanediol treated bovine pericardium material. 